\title{
Pública utilidad o causa pública: la utilidad de los conventos de la provincia de Veracruz, 1786-1834
}

\author{
David Carbajal López
}

Université Paris I Panthéon-Sorbonne

Entre 1786 y 1834 los conventos veracruzanos se justificaban a partir de la "pública utilidad", la del vecindario de una población, al cual aportaban los sacramentos, colaboraban en el mantenimiento del orden y del honor local. Tras la independencia, aparecen como nuevos argumentos la beneficencia y la educación. A finales del siglo XVIII eran considerados además benéficos al Estado, pues predicaban la obediencia al rey; mas ya entonces y sobre todo tras la independencia, comenzaron a ser considerados inútiles o incluso peligrosos para la "causa pública". Empero, el intento de exclaustración de 1834 muestra que la cultura de la "pública utilidad" tradicional mantenía su vigencia.

Palabras clave: Conventos, Veracruz, utilidad pública, secularización, causa pública.

Between 1786 and 1834 the convents of Veracruz were justified with the argument of the "public utility", that one of the neighborhood of a town, for which they used to provide the sacraments and they contributed to the maintenance of the order and the local honor. After the independence new arguments appear: the welfare and the education. At the end of eigteenth century they were also considered beneficial to the State, because they preached the obedience to the king. But then and above all after the independence, they began to be considered useless or even dangerous for the "public cause". However, the attempt of secularization of 1834 shows us that the culture of the traditional "public utility" maintained its currency.

Keywords: Convents, Veracruz, Public Utility, Secularization, Public Cause.

Durante los tres siglos de dominio de la monarquía hispánica en el reino de la Nueva España la fundación de un convento requirió de la autorización real. Las Leyes de Indias establecían claramente que, obtenida la licencia del diocesano, los solicitantes debían tener también la del virrey, Audiencia o gobernador de la jurisdicción correspondiente y presentar una información de la "urgente necesidad y justas causas" de la nueva fundación. ${ }^{1}$ Incluso después de la independencia la fundación, la conservación o

1 Recopilación de Leyes de los Reinos de Indias, libro I, tit. 3. ' ley 1, "Que se funden monasterios de religiosos y religiosas precediendo licencia del rey". 
el restablecimiento de los conventos requirió del apoyo de las autoridades civiles. ¿Cuáles eran los criterios de la "necesidad y utilidad" de los conventos? ¿Cómo cambiaron con la independencia y el liberalismo? Si era necesario probar la utilidad, ¿cuáles eran los argumentos de la "inutilidad" de estas instituciones religiosas? Tales son las preguntas a las que intentamos responder en este artículo a partir de un caso particular: los conventos de la provincia de Veracruz, estado a partir de 1824.

Aunque Veracruz era la ciudad más antigua del reino de la Nueva España, su provincia se había formalizado en fecha relativamente tardía. Hasta 1786, con la Ordenanza de Intendentes, no se constituyó la provincia de Veracruz como un gobierno propio. Algo similar puede decirse de las corporaciones religiosas veracruzanas. Si bien algunas de ellas databan de la época de la primera evangelización en el siglo XVI, durante el XVIII hubo un verdadero auge de nuevas fundaciones además de la renovación de algunas corporaciones ya existentes. Así, por ejemplo, mientras que hacia 1746 habría aproximadamente unas 40 parroquias en el territorio de la futura provincia, éstas llegarán a ser más de 60 hacia $1800 .{ }^{2}$ Un caso especialmente ilustrativo es el de la villa de Orizaba donde, en el transcurso de esta centuria, se renovaron la parroquia y la iglesia del convento hospital de San Juan de Dios y se construyeron el convento del Carmen, el Santuario de Guadalupe, el Oratorio de San Felipe Neri y tres capillas más. ${ }^{3}$

Así pues, cuando menos en la provincia de Veracruz, la fundación de nuevos conventos no era ningún recuerdo de épocas lejanas sino un hecho de especial actualidad. Aún más, las fundaciones, construcciones y reconstrucciones no se detuvieron tras la independencia, cuando menos no en algunas poblaciones. En ese sentido, el panorama de la provincia contrasta vivamente con la imagen que la historiografía ${ }^{4}$ suele presentarnos de la

2 Estimaciones hechas a partir de Villaseñor y Sánchez, José Antonio de: Theatro Americano. Descripción general de los Reynos y Provincias de la Nueva-España y sus jurisdicciones, Editora Nacional, México, 1952, y Trens, Manuel B.: Historia de Veracruz, Secretaría de Educación y CulturaGobierno del Estado de Veracruz, Xalapa, 1992, t. II, pág. 344, completada con Gerhard, Peter: Geografía histórica de la Nueva España, 1519-1821, Universidad Nacional Autónoma de México, México, 2000.

3 Véase: Arróniz, Joaquín: Ensayo de una historia de Orizaba, Biblioteca Mexicana de la Fundación Miguel Alemán / Instituto Veracruzano de la Cultura, México, 2004.

4 Véase entre otros: Brading, David: Una Iglesia asediada: el obispado de Michoacán, 17491810, Fondo de Cultura Económica (en adelante FCE), México, 2004; Jaramillo Magaña, Juvenal: Hacia una Iglesia beligerante. La gestión episcopal de Fray Antonio de San Miguel en Michoacán (1784-1804) Los proyectos ilustrados y las defensas canónicas, El Colegio de Michoacán, Zamora, 1996. Mazín Gómez, Oscar: El cabildo catedral de Valladolid de Michoacán, El Colegio de Michoacán, Zamora, 1996. Torre Curiel, José Refugio de la: Vicarios en entredicho. Crisis y desestructuración de la Provincia Franciscana de Santiago de Xalisco, 1749-1860, El Colegio de Michoacán/ Universidad de Guadalajara, México, 2001. 
situación de unas corporaciones religiosas que, en esta época, habrían visto mermados sus privilegios, subvertidas sus tradiciones y cuestionada su función por una monarquía dominada, ya por el regalismo de unos ministros ilustrados, o ya incluso por un cierto "secularismo ideológico".

$\mathrm{Y}$ sin embargo, no es menos cierto que las corporaciones religiosas veracruzanas se vieron también afectadas por las reformas emprendidas por las autoridades civiles y eclesiásticas: visitas de reforma, secularización de doctrinas, supresión de la Compañía de Jesús, etcétera. Los casos que analizamos aquí, en la medida en que nos aproximan al pensamiento de los funcionarios y munícipes, miembros de la elite de las villas veracruzanas, pueden ayudar a comprender esta aparente paradoja. Podemos adelantar que las reformas, como ha señalado Annick Lempérière, fueron implantadas por unos "ilustrados" que reconocían la necesidad de la cooperación de los actores tradicionales. ${ }^{5}$

En concreto, hacia 1786 existían catorce conventos de ocho órdenes religiosas distintas en las cuatro poblaciones más importantes de la provincia de Veracruz: franciscanos (observantes y descalzos), agustinos, dominicos, mercedarios, carmelitas, betlemitas, hipólitos y juaninos. Cuatro de ellos se fundaron en el transcurso del siglo XVIII. Sus datos generales aparecen en la tabla 1 .

En este artículo citamos de manera recurrente siete expedientes de cinco conventos. Tres de ellos fueron solicitudes de fundación: la del Colegio Apostólico de San José de Gracia de Orizaba (1794) y la de dos conventos femeninos, uno en Orizaba y otro en Xalapa (1826). En cuanto a los otros cuatro, se trata del intento de traslado del convento de San Antonio de Córdoba (1795), del restablecimiento del convento hospital de San Juan de Dios de Orizaba (1830-1834) y de los dos expedientes relacionados con la expulsión de los frailes españoles del Colegio Apostólico de San José de Gracia (1827-1829) que, como puede apreciarse, constituye el núcleo principal de nuestro estudio. ${ }^{6}$ Comencemos pues por los primeros argumentos, digamos de antemano propios todavía de la tradición del Antiguo Régimen.

5 Lempérière, Annick: "La recepción negativa de una gran idea: El absolutismo en Nueva España en la segunda mitad del siglo XVIII" en Quijada, Mónica y Bustamante, Jesús (Eds.): Elites intelectuales y Modelos colectivos. Mundo Ibérico (siglos XVI-XIX), Consejo Superior de Investigaciones Científicas, Madrid, 2000, págs. 201-203 y Lempérière, Annick: Entre Dieu et le Roi, La République. Mexico, XVIe-XIXe siècles, Les Belles Lettres, Paris, 2004, págs. 142-145.

6 Sobre San José de Gracia hemos tratado también en Carbajal Lopez, David: De frailes y seglares. Los vínculos del Colegio Apostólico de San José de Gracia de Orizaba, 1793-1840, tesis de maestría, Universidad Internacional de Andalucía-Sede Iberoamericana Santa María de La Rábida, 2006. La información que aquí se presenta aparece también en ese trabajo, aunque la perspectiva es distinta. 


\section{TABLA 1}

\section{CONVENTOS DE LA PROVINCIA DE VERACRUZ HACIA $1786^{7}$}

\begin{tabular}{|c|c|c|c|c|}
\hline Sede & Orden & Provincia & Advocación & $\begin{array}{l}\text { Fecha de } \\
\text { fundación }\end{array}$ \\
\hline \multirow{7}{*}{ Veracruz } & $\begin{array}{c}\text { Franciscanos } \\
\text { observantes }\end{array}$ & $\begin{array}{c}\text { Santo Evangelio de } \\
\text { México }\end{array}$ & San Francisco & ca. 1580 \\
\hline & Dominicos & $\begin{array}{l}\text { San Miguel y Santos } \\
\text { Ángeles de Puebla }\end{array}$ & Santo Domingo & s. XVI \\
\hline & Agustinos & $\begin{array}{l}\text { Santísimo Nombre de } \\
\text { Jesús de México }\end{array}$ & San Agustín & $?$ \\
\hline & $\begin{array}{c}\text { Real y Militar } \\
\text { Orden de la Merced }\end{array}$ & $\begin{array}{l}\text { Nuestra Señora de la } \\
\text { Visitación de México }\end{array}$ & La Merced & $?$ \\
\hline & \multirow{2}{*}{$\begin{array}{l}\text { Hermanos de la } \\
\text { Caridad (hipólitos) }\end{array}$} & $\begin{array}{c}\text { San Hipólito Mártir de } \\
\text { México }\end{array}$ & $\begin{array}{l}\text { Hospital de San Juan } \\
\text { de Montesclaros }\end{array}$ & s. XVI \\
\hline & & $\begin{array}{c}\text { San Hipólito Mártir de } \\
\text { México }\end{array}$ & $\begin{array}{l}\text { Hospital de Nuestra } \\
\text { Señora de Loreto }\end{array}$ & $?$ \\
\hline & Betlemitas & $\begin{array}{l}\text { Nuestra Señora de } \\
\text { Belén de México }\end{array}$ & $\begin{array}{l}\text { Hospital de los Santos } \\
\text { Reyes y Nuestra } \\
\text { Señora de Belén }\end{array}$ & 1745 \\
\hline \multirow{3}{*}{ Orizaba } & Juaninos & $\begin{array}{l}\text { Santo Espíritu de } \\
\text { México }\end{array}$ & $\begin{array}{l}\text { Hospital de San Juan } \\
\text { de Dios }\end{array}$ & 1618 \\
\hline & $\begin{array}{c}\text { Carmelitas } \\
\text { descalzos }\end{array}$ & San Alberto de México & San Juan de la Cruz & 1735 \\
\hline & $\begin{array}{l}\text { Franciscanos } \\
\text { observantes }\end{array}$ & & $\begin{array}{l}\text { Colegio Apostólico de } \\
\text { San José de Gracia }\end{array}$ & 1799 \\
\hline \multirow{2}{*}{ Xalapa } & $\begin{array}{c}\text { Franciscanos } \\
\text { observantes }\end{array}$ & $\begin{array}{c}\text { Santo Evangelio de } \\
\text { México }\end{array}$ & $\begin{array}{l}\text { Natividad de Nuestra } \\
\text { Señora }\end{array}$ & 1534 \\
\hline & $\begin{array}{c}\text { Hermanos de la } \\
\text { Caridad (hipólitos) }\end{array}$ & $\begin{array}{c}\text { San Hipólito Mártir de } \\
\text { México }\end{array}$ & $\begin{array}{c}\text { Hospital de San Juan } \\
\text { de Dios }\end{array}$ & 1582 \\
\hline \multirow{2}{*}{ Córdoba } & $\begin{array}{c}\text { Franciscanos } \\
\text { descalzos }\end{array}$ & San Diego de México & San Antonio de Padua & 1686 \\
\hline & $\begin{array}{c}\text { Hermanos de la } \\
\text { Caridad (hipólitos) }\end{array}$ & $\begin{array}{c}\text { San Hipólito Mártir de } \\
\text { México }\end{array}$ & Hospital de San Roque & 1723 \\
\hline
\end{tabular}

7 Sobre los conventos franciscanos y dominico: Trens, Historia, t. II, págs. 159-161, 202-203 y 238. Sobre el convento carmelita: Arróniz, Ensayo, págs. 358-360. Sobre el hospital de Orizaba, Archivo General de Indias (AGI en adelante), México, 2743, "Testimonio del Expediente formado sobre la fundacion del Hospital de Orizaba", fs. 3-4v. Sobre los hospitales hipólitos y betlemita: Muriel, Josefina: Hospitales de la Nueva España, Universidad Nacional Autónoma de México/ Cruz Roja Mexicana, México, 1991, t. I, págs. 234-235, t. II, págs. 181-182, 241-242. Sobre el Colegio Apostólico: Zulaica y Gárate, Román OFM: Monografía del Colegio Apostólico de San José de Gracia de Orizaba, separata de Asís, México, 1939. 


\section{Cambios y continuidades: la pública utilidad}

Noviembre de 1794. El factor de la Renta del tabaco de Orizaba, Bernardo María de Mendiola, es comisionado por el gobernador interino de Veracruz para levantar la información acerca de la necesidad y utilidad de la fundación de un colegio apostólico en esa villa. Mendiola interroga a seis testigos y prepara un informe que envía al gobernador con fecha 30 de enero de 1795. Este alto funcionario es claramente favorable a la apertura del nuevo convento: es necesario, afirma, pues en el curso de los anteriores treinta años la villa de Orizaba ha duplicado el número de sus habitantes, su vecindario, como también han aumentado sus riquezas, el "pasto corporal", mas no así el "pasto espiritual". "La mies es mucha y pocos los operarios", asevera el factor citando los Evangelios. ${ }^{8}$

Conviene tener presente que los colegios apostólicos eran conventos destinados no tanto al servicio de las poblaciones en donde se encontraban establecidos, sino más bien a recorrer los pueblos, ya cercanos, ya distantes, predicando misiones entre fieles e infieles incluso en las regiones más recónditas del reino. ${ }^{9}$ Pero el informe de Mendiola piensa la utilidad del convento de manera mucho más local: para el funcionario los religiosos completarían el "socorro espiritual" que proporcionaban ya las otras corporaciones religiosas de la villa (el Oratorio de San Felipe Neri y el convento del Carmen), socorro que, en concreto, se refiere a la impartición de los sacramentos, especialmente la confesión y la comunión anuales, "el precepto pascual" a que estaban obligados todos los habitantes del reino. ${ }^{10}$

Empero, Mendiola veía bien que el de los colegios apostólicos era también un instituto misionero. Elogiaba los resultados de las misiones predicadas en 1777 y 1793, las cuales, dice, convirtieron a Orizaba "en otra Nínive". " Aún más, la sola presencia de los misioneros, "mantuvo el fer-

8 AGI, México, 1304, “Testimonio del expediente formado en virtud de comisión por el factor D. Bernardo María de Mendiola sobre la fundación de un Colegio de RR.PP. Misioneros Apostólicos en la Villa de Orizaba”, fs. 31v-36, Bernardo María de Mendiola a Pedro Ponce, Orizaba, 30 de enero de 1795. La cita procede, desde luego, de los evangelios sinópticos (Mateo, 9:37; Marcos, 6: 8; Lucas, 10:2).

9 Sobre los colegios apostólicos véase: Sáiz Díez, Félix, OFM: Los Colegios de Propaganda Fide en Hispanoamérica, Madrid, 1969.

10 Sobre el cumplimiento del precepto pascual en la Nueva España, Taylor, William B.: Ministros de lo sagrado. Sacerdotes y feligreses en el México de la segunda mitad del siglo XVIII, El Colegio de Michoacán/ Secretaría de Gobernación/ El Colegio de México, Zamora, 1999, vol. I, págs. 359-362.

11 Alude desde luego al capítulo 3 del libro de Jonás que narra la conversión de Nínive tras la predicación de dicho profeta. 
vor" y "contuvo la relajación". Las misiones populares, debemos recordarlo, tenían como fin obtener la penitencia de los pecadores, moviendo para ello las emociones de los fieles, especialmente el miedo, utilizando a este fin los recursos más variados: sermones y procesiones, pero también representaciones, imágenes, versos, todos relacionados con los castigos infernales que amenazaban al pecador que muere sin haberse arrepentido. ${ }^{12}$

El nuevo convento, se entiende, serviría para asegurar la conversión de los orizabeños más allá de las prédicas cuaresmales y ocasionales, manteniéndolos así de manera permanente, si no en un estado penitencial, al menos en el buen orden querido por las autoridades civiles y eclesiásticas. Ya decían los apoderados del Ayuntamiento y clero orizabeños, que con las prédicas de los frailes se habían:

sofocado los vicios, refrenádose generalmente las costumbres y exterminádose el lujo y [la] ociosidad, pésimas raíces de cuantos daños lamenta la experiencia, comenzaron luego a percibirse los suaves aromas de las virtudes, y a admirarse como objeto de edificación cristiana. ${ }^{13}$

"Imponderables beneficios espirituales y temporales", agregaría el Cabildo de naturales de la propia villa, que no dudaba en calificar el nuevo convento como un establecimiento de "pública utilidad". ${ }^{14}$

Detengámonos un momento. Hemos dicho "pública utilidad" y tal parece ser la expresión que mejor resume los argumentos hasta aquí presentados. Tanto para el factor de la Renta de tabaco como para los representantes del clero y repúblicas de españoles e indios de Orizaba, el nuevo convento redundaría ante todo en beneficio del "público", es decir, del conjunto de habitantes de la villa de Orizaba, del cual eran los portavoces naturales. Sobra decir que no se trata aquí de beneficios materiales, sino espirituales, necesarios para la salvación de las almas, uno de los fines que legitimaba la existencia de toda comunidad en esta época. ${ }^{15}$

12 Al respecto puede verse, entre muchos otros, Prosperi, Adriano: "El misionero", en Rosario Vilari (ed.), El hombre barroco, Alianza Editorial, Madrid, 1992, págs. 201-239. Morán, Manuel y José Andrés Gallego: "El predicador" en Ibidem, págs. 165-199. Châtellier, Louis: La religión de los pobres. Europa en los siglos XVI-XIX y la formación del catolicismo moderno, Desclée de Brouwer, Bilbao, 2002, págs. 69-79.

13 AGI, México, 1304, “Testimonio del expediente formado en la Secretaría del Obispado e Ilustrísimo Obispo de Puebla sobre licencia para la fundación de un Colegio Apostólico de Misioneros en Orizaba”, fs. 1-7, José Francisco de Ordosgoiti y José Antonio Suárez Melo al obispo de Puebla, sin fecha.

14 Ibídem, fs. 37-39v, el Cabildo y común de naturales de Orizaba al obispo de Puebla, Orizaba, 28 de octubre de 1793.

15 Lempérière, Entre Dieu, págs. 27-29. 
La cuestión del orden público es una de las constantes de todo el periodo que tratamos. Décadas más adelante, en 1829, cuando el tema ya no sea la fundación del colegio apostólico sino su conservación, el Ayuntamiento de Orizaba - ya no el del Antiguo Régimen, formado por regidores perpetuos, sino uno constitucional, electivo- se expresará en los mismos términos. Los munícipes argüirán entonces que el convento "ha contribuido a mantener incorruptas las costumbres de un pueblo que los respeta y aprecia". ${ }^{16}$ Los propios vecinos orizabeños habían ya descrito la de los frailes como una labor de orden moral y afirmaban: "tienen enfrenadas las costumbres de estos pueblos, tienen en la órbita de sus deberes, al padre de familia, a la esposa y al hijo, éstos por último son los únicos que derraman la moral pura en este cantón". ${ }^{17}$

Así pues, los conventos proveían el pasto espiritual y contribuían a mantener el orden, mas su fundación era también una cuestión de honor. En aquel año de 1795, mientras corrían los largos y engorrosos trámites de la fundación del colegio apostólico orizabeño, en la cercana villa de Córdoba el Ayuntamiento tuvo la noticia de que el convento de San Antonio de Padua, de religiosos franciscanos descalzos, estaba en vísperas de trasladarse a la villa de Orizaba por decisión del Definitorio provincial. El traslado, cabe aclarar, no llegará a realizarse, ni hemos encontrado documentos que den siquiera cuenta de los procedimientos comunes en estos casos. Pero la sola noticia, llegada a los munícipes a través de vías informales — una carta de un religioso remitida a un vecino de Orizaba, quien a su vez la envía a un vecino de Córdoba,$-{ }^{18}$ fue suficiente para alarmar a los representantes del público.

Notemos en principio que, a pesar de tratarse del único convento de la villa, los miembros del Ayuntamiento nada dicen de la falta que harían los religiosos para la administración del "pasto espiritual". La "novedad escandalosa", según la calificaba el Cabildo, justicia y regimiento cordobés, lo era porque "cede en grave desaire y deshonor", "injuria y agravio" del "inocente público". Así, los munícipes no reclaman la permanencia del convento, no pretenden "violentar el albedrío" de los frailes, suplican en

16 Archivo General de la Nación, México (AGN, en adelante), Expulsión de españoles, 35, fs. 110-113, representación del Ayuntamiento de Orizaba al presidente de la República, abril de 1829.

17 AGN, Justicia eclesiástica, 68, fs. 105-106v, representación del pueblo de Orizaba, diciembre de 1827.

18 Conviene decir que los involucrados no eran unos vecinos comunes: se trataba del teniente coronel Marcos González, oficial de milicias provinciales, y de Andrés Chanteiro, "vecino republicano" de la villa de Córdoba. 
cambio al virrey que se ordene al Definitorio "exponga inmediatamente las causales que les asisten para haber dictado una providencia tan ligera", y así obtener la satisfacción debida al honor de la villa. ${ }^{19}$

El escándalo de los munícipes cordobeses se entiende en el contexto de la época. Una corporación territorial, como la villa, debía una parte importante de su prestigio a la presencia en su seno de un buen número de corporaciones religiosas. Las descripciones que en la época se hacían de cualquier ciudad, villa o pueblo, resaltaban normalmente el número y belleza de las iglesias y capillas, la abundancia de su clero y la riqueza de sus conventos..$^{20} \mathrm{~A}$ su vez, la elección de una población en particular para la instalación de una nueva corporación iba relacionada con el prestigio de ésta. No otro era el argumento, por ejemplo, que el Ayuntamiento de Veracruz exponía en 1802 para que se instalara allí una sede episcopal. Correspondía a Veracruz, decían los munícipes, "por ser ésta la primera y más antigua Ciudad de este vasto reino, donde su heroico conquistador D. Fernando [sic] Cortés sembró las primeras semillas del Evangelio, y se rindió a la obediencia del rey católico". ${ }^{21}$ En esa lógica, los cabildantes cordobeses se expresaban con toda razón: si la instalación de una corporación religiosa retribuía al honor de un pueblo, su traslado repentino iba, en efecto, en desdoro del honor del público cordobés.

Aquí nuevamente nos encontramos con más continuidades que cambios. Unas décadas más tarde, la lógica no era distinta. En junio de 1826, más de tres décadas han pasado desde los expedientes iniciados en Orizaba y Córdoba. Una guerra, o mejor dicho una revolución liberal, ha tenido lugar, y el reino de la Nueva España ha dejado paso a un Imperio, primero, y luego a una República que se organizan bajo nuevos principios. Entonces, el Ayuntamiento de Xalapa -insistimos, una institución que ahora es electiva y ya no privilegiada - recibe la solicitud de sor María Bárbara de la Concepción, religiosa carmelita descalza, pidiendo su apoyo para la fundación de un convento en esa villa. ${ }^{22}$

Apenas tres días después, se lee en cabildo la respuesta preparada a tan "interesante objeto". Con la elección de Xalapa, afirmaron los muníci-

19 AGN, Clero regular y secular, 188, 14, fs. 249-251, el Cabildo, justicia y regimiento de la villa de Córdoba al virrey, Córdoba, 25 de noviembre de 1795.

20 Véase por ejemplo para la ciudad de México: Lempérière, Entre Dieu, págs. 101-103.

21 AGI, México, 2603, representación del Ayuntamiento de Veracruz del 22 de diciembre de 1802, copia hecha en Veracruz, 10 de abril de 1813.

22 Archivo Histórico Municipal de Xalapa (AHMX, en adelante), Libro de acuerdos de Cabildo de 1826, Cabildo extraordinario del 23 de junio, fs. 65v-66. 
pes, “el ayuntamiento se posee de una dulce y santa emoción”. La ciudad se convertía en la "Santa Jerusalén" de la venerable religiosa, "escogida [para] prodigarle los inmemorables bienes reservados a sus escogidos". Toda vez que la religiosa había fundado ya antes dos conventos en las ciudades de Querétaro y Valladolid de Michoacán, Xalapa, lo percibían de inmediato los ediles, se veía comparada con ambas poblaciones, cuyo título de ciudad las colocaba un peldaño más arriba en la jerarquía de las corporaciones territoriales. La "selecta Xalapa", decían, no cedía a Valladolid "en religiosidad, ilustración y patriotismo". ${ }^{23}$

Los fines espirituales del convento femenino fueron, asimismo, debidamente señalados. Claro está que las religiosas no podían ni predicar ni impartir sacramentos, su función no era, propiamente hablando, administrar el pasto espiritual al público. En cambio, este "primer claustro de vírgenes" otorgaría a Xalapa "aquella garantía de seguridad que una alma justa alcanzó mil veces, calmando las iras del Cielo, por su intercesión a favor del pueblo pecador". ${ }^{24}$

Tal pues, la utilidad de los conventos en la perspectiva de las autoridades locales, o por mejor decir, de la "pública utilidad" tradicional: orar por el pueblo, proveer el pasto espiritual, contribuir al mantenimiento del orden y aumentar el honor de la corporación. Estas formas de utilidad permanecen constantes a lo largo de todo el período que tratamos; sin embargo, no todo fueron continuidades. Debemos destacar también la aparición de otras formas nuevas de la "utilidad pública", dos en particular: la beneficencia y la educación, visibles en la relación con los conventos hospitales y en los proyectos de fundación de conventos femeninos.

Entre los conventos de la provincia de Veracruz, los hospitales ocupaban un lugar especialmente destacado. En las cuatro poblaciones más importantes había cuando menos un hospital atendido por religiosos, ya fueran juaninos, hipólitos o betlemitas. Como cualquier otro convento, habían requerido en su momento la autorización de ambas potestades, civil y eclesiástica; y lo mismo que otras corporaciones, disfrutaban de una amplia autonomía, si bien estaban sometidos a la disciplina de sus respectivas provincias. Mas en la segunda mitad del siglo XVIII, tanto la Monarquía como el Episcopado y algunos Ayuntamientos comenzaron a

23 AHMX, Libro de acuerdos de cabildo de 1826, fs. 143-144, minuta de la representación del Ayuntamiento de Xalapa al Congreso del Estado, Xalapa, 26 de junio de 1826.

24 Ibidem. 
intervenir de manera creciente en el gobierno de los hospitales, los cuales, faltos muchas veces de recursos — sobrevivían de limosnas y de algunas fundaciones piadosas-, pasaban por serias dificultades materiales y disciplinarias. $^{25}$

En su calidad de representantes del vecindario, los Ayuntamientos de la época llegaron incluso a asumir la administración de los hospitales, aunque siguieran atendidos por religiosos. Tal fue el caso, en Veracruz, de los hospitales de San Juan de Montesclaros y Nuestra Señora de Loreto, originalmente a cargo de frailes hipólitos. ${ }^{26}$ Pocos años más tarde, con el estallido de la guerra en 1810, los hospitales se vieron desbordados con la atención que debían brindar a las tropas que defendían las poblaciones de los ataques insurgentes. ${ }^{27}$ Nuevamente, los Ayuntamientos, especialmente en Xalapa y Orizaba, debieron intervenir para que la atención hospitalaria pudiera sostenerse. ${ }^{28}$ La Constitución de Cádiz de 1812, al asignar a los nuevos Ayuntamientos liberales la obligación de cuidar por los hospitales, no hizo sino formalizar una situación de hecho. ${ }^{29}$

No podemos entrar aquí en las discusiones que tuvieron lugar al otro lado del Atlántico, mas debemos señalar un punto fundamental: si las Cortes gaditanas habían puesto a los hospitales bajo la supervisión de los Ayuntamientos, las Cortes del Trienio Liberal fueron más allá y suprimieron directamente las órdenes hospitalarias como parte de su proyecto de reforma de los religiosos, que se concretó en la llamada "ley de monaca-

25 Para la Nueva España en general: Zahino Peñafort, Luisa: Iglesia y sociedad en México, 1765-1800. Tradición, reforma y reacciones, Universidad Nacional Autónoma de México-Instituto de Investigaciones Jurídicas, México, 1996, págs. 114-165; sobre los hospitales juaninos: Alberro, Solange: Apuntes para la historia de la Orden Hospitalaria de San Juan de Dios en la Nueva EspañaMéxico, 1604-2004, El Colegio de México/ Orden Hospitalaria de San Juan de Dios, México, 2005; para los hospitales de la ciudad de Veracruz: Cruz Velázquez, Romeo: Los hospitales del puerto de Veracruz, 1760-1800, Instituto Veracruzano de la Cultura, Veracruz, 1998.

26 Muriel, Hospitales, t. II, págs. 21-27, 235-239. Cruz, Hospitales, págs. 154-155 y 162.

27 Sobre la guerra en la provincia de Veracruz, véase: Ortiz Escamilla, Juan: "Revolución y liberalismo en la Provincia de Veracruz, 1812-1821”, Revista de Indias, LXII-225, Madrid, 2002, págs. 409-428. Y del mismo autor: El Teatro de la Guerra. Veracruz, 1750-1825, FCE, México, en prensa.

28 Véase: AHMX, Libro de acuerdos de cabildo de 1814, acta de cabildo extraordinario de 29 de diciembre, fs. 29-31v. Archivo Histórico Municipal de Orizaba (AHMO en adelante), "Libro de acuerdos del Ilustre Ayuntamiento celebrados desde el año de 1815 hasta el año de 1822", acta del cabildo de 9 de octubre de 1816.

29 "Constitución Política de la Monarquía Española", artículo 321, en Tena Ramírez, Felipe: Leyes fundamentales de México, 1808-1997, Porrúa, México, 1997, pág. 97. "Instrucción para el gobierno económico-político de las provincias, decretada por las Cortes Generales y Extraordinarias", artículo 1, en La Constitución de 1812 en la Nueva España, Archivo General de la Nación, México, 1912, t. I, pág. 258. 
les" de octubre de $1820 \cdot{ }^{30}$ Pero el decreto, aunque llegó a la Nueva España a finales de ese mismo año, tuvo muy desigual cumplimiento a todo lo largo del reino. En la provincia de Veracruz simplemente no tuvo efecto aunque, evidentemente, los conventos hospitales quedaban a partir de entonces en una situación, cuando menos, frágil.

Fueron los propios Ayuntamientos los que insistieron en que los hospitales siguieran siendo conventos hospitales, es decir, continuaran atendidos por religiosos. Así, en marzo de 1822, los miembros del Ayuntamiento de Orizaba "convinieron por aclamación" en solicitar al Congreso Constituyente el restablecimiento de las órdenes hospitalarias arguyendo la "necesidad y utilidad que resulta al público". ${ }^{31}$ Los munícipes actuaban en consecuencia: como nunca antes, las actas del Cabildo orizabeño dan cuenta de la correspondencia entre esa corporación y el prior de San Juan de Dios, la primera insistiendo en intervenir en las finanzas del convento para completarlas con los fondos municipales, y el segundo negándose sistemáticamente a presentar la información requerida, amenazando con abandonar el establecimiento. ${ }^{32}$

La intervención de los integrantes del Ayuntamiento reviste una novedad: el imperativo de la eficiencia. La atención a los enfermos no aparece tanto como un deber de la caridad cristiana, cuanto como un medio para atender la enfermedad misma ${ }^{33}$ De ahí que los regidores insistan en que los religiosos deben atender a todos los enfermos que acudieran al hospital, mientras que los frailes recibían sólo a aquéllos que podían ser mantenidos con sus rentas.

Cabe decir que también en Xalapa el Ayuntamiento recibió una solicitud de entregar el hospital por parte del prior juanino desde $1821 .{ }^{34}$ Tanto en esa villa como en Orizaba los religiosos terminarán, efectivamente, por

30 "Decreto de supresión de monacales y reforma de regulares aprobado por las Cortes el 1 de octubre, y sancionado por el Rey el 25 de octubre de 1820 ”, artículos $1 .^{\circ}, 7 .^{\circ}, 8 .^{\circ}, 14$ y 22 , en Revuelta González, Manuel, S.J.: Política religiosa de los liberales en el siglo XIX, Consejo Superior de Investigaciones Científicas-Escuela de Historia Moderna, Madrid, 1973, págs. 387-390.

31 AHMO, "Libro de acuerdos del Ilustre Ayuntamiento celebrados desde el año de 1815 hasta el año de 1822", acta de cabildo del $1 .^{\circ}$ de marzo de 1822.

32 Ibidem, "Libro de acuerdos del Ilustre Ayuntamiento celebrados en los años de 1823, 1824, 1825 y 1826", actas de cabildo de 23 de enero, 22 de febrero, 22 de abril, 6 y 13 de junio, 4 de julio, 8 de agosto, 7 y 28 de noviembre de 1825 y de 16 de enero, 2 de febrero y17 de abril de 1826 .

33 Cfr. Alberro, Apuntes, págs. 232-235.

34 AHMX, Libro de acuerdos de cabildo de 1826, fs. 224-224v, minuta del Ayuntamiento de Xalapa al Lic. José María Prieto, jefe de Departamento. 
abandonar sus conventos, en el primer caso desde 1822, en el segundo en 1827. Pero los munícipes orizabeños no dejaron de insistir.

Octubre de 1830. Hacía tres años que los frailes abandonaron el convento hospital de San Juan de Dios de Orizaba, dejándolo a cargo del Ayuntamiento. El regidor Jacinto Font propone entonces solicitar al Congreso del Estado el restablecimiento de los frailes y para apoyar la idea arguye que el hospital implica crecidos gastos a la municipalidad, así como la atención de alguno de los regidores, más allá del peso que de por sí implicaban las cargas concejiles, que por serlo, cabe recordarlo, eran gratuitas. Se imponen de nuevo los argumentos de la necesidad y la utilidad: "es de necesidad solicitar de nuevo los religiosos quienes por solamente la comida y un triste hábito desempeñan tan gravosas obligaciones", alega Font. ${ }^{35}$

Y efectivamente, el convento hospital sería reabierto el 25 de agosto de 1834 y para el año siguiente ya era habitado por siete religiosos, una cifra no vista cuando menos desde mediados del siglo XVIII. ${ }^{36}$ Empero, no se trata estrictamente de una vuelta atrás. Ya lo habían propuesto algunos de los regidores en 1830, pero el convento reabierto no habría de recuperar toda su autonomía, antes bien quedaba estrictamente bajo la vigilancia del Ayuntamiento, al que debía rendirle cuentas mensualmente y del que obtendría los fondos para completar sus gastos.

Ahora bien, repetimos, la beneficencia no era el único justificante nuevo para la apertura de un convento. En agosto de 1826, el Cabildo de Orizaba recibe un memorial de sor Juana María de Guadalupe, religiosa carmelita de México, pidiendo su apoyo para la fundación de un convento de su orden en la villa. ${ }^{37}$ Contrario a los munícipes xalapeños, que hemos visto en la misma época muy entusiastas al apoyar una solicitud semejante, los orizabeños se limitaron a nombrar una comisión que consultara el asunto con el párroco. Éste, que era el doctor Francisco García Cantarines, propone "se conteste a la monja preguntándole si no será compatible la enseñanza de niñas con su profesión". La comisión apoyó la idea, pero no todos los munícipes estuvieron de acuerdo: "preguntar a la monja si puede relajar el voto de su recolección para dedicarse a la enseñanza es ponerse

35 AHMO, "Libro de acuerdos del Ilustre Ayuntamiento celebrados en los años de 1830 y 1831", fs. 104-105, acta de cabildo de 20 de octubre de 1830.

36 Ibidem, "Libro de acuerdos del Ilustre Ayuntamiento celebrados en los años de 1832, 1833 y 1834", actas de cabildo de 6 y 26 de agosto de 1834. Alberro, Apuntes, pág. 130.

37 Ibidem, "Libro de acuerdos del Ilustre Ayuntamiento celebrados en los años de 1823, 1824, 1825 y 1826 ", acta de cabildo de 21 de agosto de 1826. 
en ridículo la corporación", sentenció el presidente de la sesión. ${ }^{38}$ La discusión, que lamentablemente no fue asentada en las actas de cabildo, concluyó con una nueva consulta al párroco.

Los integrantes del gobierno local debieron dedicar una segunda sesión a este mismo asunto. La división es evidente. Mientras que el teniente coronel José María Mendizával insiste: "no cumpliría con sus deberes sino pidiera como lo hace que la corporación solicite licencia del gobierno para el establecimiento"; el presidente de la sesión, alcalde Manuel Elías Ximénez, responde contundente: "ninguna utilidad resulta a la población con un establecimiento de religiosas que sólo van hacer (sic, ¿a ser?) útiles a sí mismas". ${ }^{39}$

Hay un cambio patente sin duda: ni el párroco García Cantarines, ni el alcalde Ximénez reconocen en el convento femenino otra utilidad que no sea la instrucción de niñas. Sin embargo, en lo que a la educación concierne, no se trata de una idea completamente original: desde mediados del siglo XVIII existían ya en la Nueva España conventos femeninos dedicados a la educación, los de la Compañía de María. ${ }^{40}$ Mas en el contexto de la época, los años 1820, la insistencia en la educación refleja también una posición política: la de la nueva cultura política liberal, que espera por ese medio renovar la sociedad..$^{41}$

En ese sentido, las posiciones expresadas en el Cabildo orizabeño no son producto del azar. Orizaba conoce entonces la formación de las primeras facciones de la época, una de las cuales, la de los moderados, identificada en la historiografía tradicional como ligada a la masonería de rito escocés, mantuvo el control de las principales corporaciones de la villa entre 1825 y 1828 . Entre sus principales representantes estaba el jefe político Vicente de Segura, su secretario el licenciado Rafael Argüelles Rendón, el hermano de éste, Manuel Argüelles y Rendón, diputado por Orizaba en diversos congresos federales, entre otros vecinos "de opinión". ${ }^{42}$ El doctor García Cantarines, sino era miembro, cuando menos era bien vis-

38 Ibidem, "Libro de acuerdos del Ilustre Ayuntamiento celebrados en los años de 1823, 1824, 1825 y 1826", acta de cabildo de 5 de septiembre de 1826 .

39 Ibidem, "Libro de acuerdos del Ilustre Ayuntamiento celebrados en los años de 1823, 1824, 1825 y 1826", acta de cabildo de 12 de septiembre de 1826.

40 Notas generales sobre estos conventos en: Brading, Iglesia, pág. 111.

41 Al respecto, Lempérière, Annick: "De la República corporativa a la Nación moderna. México (1821-1860)" en Annino, Antonio y Guerra, François-Xavier (coords.): Inventando la Nación. Iberoamérica siglo XIX, FCE, México, 2003, págs. 327 ss.

42 Sobre las facciones orizabeñas: Arróniz, Ensayo, págs. 647-650. 
to por esa facción. Antiguo diputado por Córdoba del Congreso constituyente de Veracruz, el eclésiástico se distinguió por su respaldo a iniciativas que fortalecían al nuevo Estado frente, incluso, a la potestad episcopal. ${ }^{43}$ Con tal antecedente, no es de extrañar que el Ayuntamiento recibiera con complacencia su nombramiento como párroco, ni que hiciera cuanto estuvo a su alcance para acelerar su llegada.

A pesar de la influencia de esta facción, no por ello lograban siempre imponer sus puntos de vista. En el expediente que tratamos, luego de una larga discusión, el Cabildo acabó por dar su apoyo sin condiciones a la solicitud de la religiosa carmelita. Como muestra de su desaprobación, el alcalde Ximénez prefirió abstenerse.

Ahora bien, como en el caso de los conventos hospitales, si bien los argumentos son nuevos, se integran sin dificultad en un marco tradicional. Estamos, otra vez, ante la utilidad del público, la del vecindario, la de la corporación territorial. "Ninguna utilidad resulta a la población", había dicho claramente el alcalde primero orizabeño. No menos tradicional es la preocupación expresada por el "ridículo" de la corporación. A pesar de ser miembros de un nuevo tipo de institución, el Ayuntamiento constitucional, los munícipes eran bien capaces de hacer esfuerzos por conciliar tradición y modernidad, los conventos y los nuevos fines de la comunidad. Empero, muy distinta es la historia, a otro nivel, de un cuerpo político más amplio, la Monarquía, que dará paso en el siglo XIX al Estado liberal.

\section{La ruptura: inútiles y peligrosos para la "causa pública"}

Volvamos por un momento a la fundación del Colegio Apostólico de San José de Gracia de Orizaba. Obtenida la licencia episcopal y la del virrey, el expediente se envió al Consejo de Indias en Madrid, adonde acudió también, para atender los trámites necesarios, fray Juan Buenaventura Bestard, en calidad de comisario encargado de la nueva fundación tanto por parte del clero como del Ayuntamiento orizabeños. El fraile debió dirigirse al Consejo en dos ocasiones para exponer sus argumentos a favor del que habría de ser su nuevo convento. Destaquemos sólo una de las ideas de su

43 Sobre la política eclesiástica del Congreso constituyente veracruzano, Carbajal López, David: La política eclesiástica del estado de Veracruz, 1824-1834, INAH/ Miguel Ángel Porrúa, México, 2006, págs. 47-60. 
segunda exposición, la más larga, en respuesta a los dictámenes negativos del fiscal Ramón de Posada:

La razón, la experiencia y la autoridad, todo, Señor, nos ha enseñado de un modo nada equívoco que la Religión con sus santas ilustraciones es la que más contribuye a la seguridad y felicidad del Estado; que los mejores cristianos son los vasallos más útiles, y más fieles; y que el radicar los Pueblos con las verdades de nuestra Santa Fe, y en la caridad cristiana, es el medio más apropósito para asegurarlos en la verdadera paz, y en la debida subordinación... ${ }^{44}$

Aclaremos, en principio, que fray Juan Buenaventura no se refiere a la concepción moderna del Estado como potestad pública, sino al cuerpo político de la Monarquía, encabezado por el rey, ciertamente, pero incluyendo en su seno toda la densa trama del gobierno corporativo, o, lo que es lo mismo, a la sociedad en su conjunto. ${ }^{45}$ Mas para nuestro fraile fundador la "felicidad del Estado" aparece sobre todo identificada con la subordinación al rey. ¿Argumento propio de la estrategia de un fraile en la Corte? Sin duda, pero no por ello menos ilustrativo de lo que los religiosos consideraban su deber. Conviene decir que, a lo largo de su carrera, fray Juan se mantuvo coherente en esa idea y obtuvo las recompensas correspondientes: después de obtener la fundación del nuevo Colegio y el envío de frailes peninsulares en dos ocasiones, el padre Bestard será el primer guardián de San José de Gracia y, una vez jubilado y vuelto a su natal Mallorca, será también, desde 1816, el último comisario general de las provincias y colegios franciscanos de Indias. ${ }^{46}$ Apenas llegado a ese cargo, enviará a sus súbditos, es decir, a los frailes bajo su jurisdicción, una extensa carta pastoral recordándoles sus deberes con el rey, de la que no podemos evitar citar cuando menos un pasaje. Ordenaba fray Juan a todos sus religiosos y religiosas:

Acreditad vuestra fidelidad en el púlpito; acreditadla en el confesionario; acreditadla en vuestras conversaciones familiares, aun [en] las más confidenciales; acreditadla en vuestras cartas, y los que tienen luces para ello, acredítenla también en sus escritos e impresos. Desengañad a cuantos podáis, haced que todos los pueblos se declaren por

44 AGI, México, 1304, exposición de fray Juan Buenaventura Bestard, 16 de mayo de 1797.

45 Lempérière, Annick: "Reflexiones sobre la terminología política del liberalismo" en Connaughton; Brian, Illades, Carlos y Pérez Toledo, Sonia (coords.): La construcción de la legitimidad política en México, El Colegio de Michoacán/ Universidad Autónoma Metropolitana-Unidad Iztapalapa/ Universidad Nacional Autónoma de México/ El Colegio de México, México, 1999, págs. 43-49.

46 La carrera del padre Bestard en: Zulaica, Monografía. 
el Soberano, que proporcionen al gobierno todas las noticias y todos los auxilios convenientes y que no encuentren en ellos los rebeldes ninguna acogida. ${ }^{47}$

Pero volvamos a los actores que nos interesan. ¿Compartían las autoridades civiles la idea de que los conventos eran útiles al Estado? En mayo de 1795, al pasar el expediente de la fundación del Colegio de San José de Gracia por el fiscal de lo civil de la Audiencia de México, éste dictaminó precisamente estar persuadido de sus beneficios para "el público, el Estado y la Religión". El fiscal Borbón fundaba su dicho en "las Leyes del Reino", y en "el religioso ánimo de Su Majestad que atiende como primer objeto la propagación de la fe". ${ }^{48}$ Otro tanto dirá, en 1818, el asesor general del virreinato cuando se trate de conceder al mismo Colegio la licencia para reclutar en la Península nuevos religiosos: como éstos serían enviados para la "conversión de infieles" en California, el funcionario evocaba el papel de los frailes en la construcción misma del reino, habiendo realizado "en gran parte la feliz consumación de la conquista". ${ }^{49}$

Tenía razón el fiscal Borbón al indicar que el "primer objeto" de la monarquía era la propagación de la fe. No olvidemos el contexto, se trata de la Monarquía Católica, que debe parte de su legitimidad, especialmente en lo que concierne a los reinos americanos, a su compromiso con la expansión y defensa de la fe. ${ }^{50}$ Incluso bajo el reformismo borbónico la jerarquía de valores, que situaba la fe en primer lugar, se mantenía indiscutible. ${ }^{51}$ Por ello la protección de los religiosos formaba parte de las regalías de la Corona en materia eclesiástica, facultades del soberano "para hacer observar las leyes de la Iglesia y su disciplina en calidad de protectores, conservadores y ejecutores de ellas", según escribía un jurista de la época. Respecto de los conventos, las regalías permitían al monarca lo mismo admitir una nueva orden en sus reinos, siempre que fuese "útil y ventajosa

47 Pastoral del Comisario General de Indias a sus súbditos, Oficina de Don Francisco Martínez Dávila, Impresor de Cámara de Su Majestad, Madrid, 1816, s.n.p.

48 AGI, México, 1304, "Testimonio del expediente formado sobre fundación de un colegio de Misioneros Apostólicos de la Regular observancia en Orizaba”, fs. 3-5v, parecer del fiscal de lo civil, México, 15 de mayo de 1795.

49 AGN, Misiones, 11, fs. 169-170, parecer del asesor general Velasco, México, 9 de febrero de 1818.

50 Conviene decir que la Monarquía hispánica no era, en este sentido, muy distinta al resto de las monarquías europeas, véase por ejemplo Remond, René: Religion et société en Europe. La sécularisation aux XIX et $X X^{e}$ siècles, 1789-2000, Seuil, Paris, 2003, págs. 44-49.

51 Véase: Lempérière, Entre Dieu, 2004, pág. 170ss. 
a la religión y a la sociedad", que incluso expulsarla, mediando en uno u otro caso "justas causas". 52

"Justas causas públicas" _."público" aquí nuevamente en su sentido tradicional - eran las que el monarca alegaba siempre en justificación de sus decisiones. El padre Bestard insistirá en que el nuevo convento las había reunido lo suficiente para "mover al real ánimo" con los testimonios de párrocos, obispos, Cabildos de españoles e indios y desde luego del virrey. Pero en aquellos finales del siglo XVIII, había ya algunas voces importantes que no estaban del todo de acuerdo en la utilidad de los conventos para la Corona.

En efecto, hemos dicho que el padre fundador, fray Juan Buenaventura Bestard, debió dirigirse al Consejo de Indias en dos ocasiones para obtener la aprobación del nuevo convento; en ambas, sus memoriales recibieron respuestas negativas del fiscal del Consejo para Nueva España, don Ramón de Posada, antiguo fiscal de la Real Hacienda de México. ${ }^{53}$ Los dictámenes del fiscal nos permiten conocer los argumentos contrarios a la apertura de los conventos, por decirlo de alguna forma, los de la "inutilidad" de éstos.

En su primer dictamen el funcionario se mantuvo en la lógica del pasto espiritual: estimó bien el número de eclesiásticos de Orizaba en 42 ó 43, pero subestimó el tamaño de la población, que calculó en 600 vecinos, siendo que toda la doctrina tenía más de nueve mil almas en 1777.54 Para él, por tanto, la villa contaba con número más que suficiente de sacerdotes. Pero Posada fue más lejos.

Como buen jurista, el fiscal recuperó una consulta del Consejo de Castilla de 1619, elaborada por el canónigo Pedro Fernández de Navarrete, donde se afirmaba claramente: la "universal conservación de la Corona" no consistía sino "en la mucha población y abundancia de gente útil y provechosa”. Las órdenes religiosas reducían esa población y sus bienes, ya al

52 Covarrubias, José: Máximas sobre recursos de fuerza y protección con el método de introducirlos en los tribunales, Imprenta de la Viuda de Ibarra, Madrid, 1783, págs. 170 y 187-204.

53 Sobre el fiscal Posada puede verse: Rodríguez García, Vicente: "El fiscal Posada: índice para una biografía", Anuario de Estudios Americanos, XXXIV, Sevilla, 1977, págs. 187-210 y El fiscal de Real Hacienda en Nueva España: Don Ramón de Posada y Soto, 1781-1793, Universidad de Oviedo, Secretariado de Publicaciones, Oviedo, 1986.

54 De acuerdo al padrón levantado en 1777, la feligresía de la parroquia de Orizaba se componía de 9917 almas, entre las cuales se contaban 52 eclesiásticos, incluidos tanto clérigos como religiosos. AGI, México, 2580, "Padrón general de la Muy Leal Villa de Orizaba y sus anexos del año de 1777 ", fs. $215 \mathrm{v}$ y $234 \mathrm{v}$. 
convertirlos en bienes eclesiásticos, ya al recargarlos de limosnas, como era en el caso de los mendicantes. A estos últimos, que se dedicaban a recoger limosnas en especie entre los labradores de la comarca de sus conventos (las "cuestas", como se les denominaba entre los franciscanos), el fiscal no dudaba en compararlos con una plaga: "cargaban tantos, y tan importunos demandantes sobre los carneros y sobre los demás frutos, que acosaban a los criadores y cosecheros a manera de langosta". En suma, los conventos eran "muy dañosos y perjudiciales para lo público". ${ }_{55}$

Notemos en principio el cambio en el sentido de "público", que no es aquí un vecindario, sino la Corona misma. En segundo lugar, aunque Posada utiliza un recurso muy tradicional, un antecedente jurídico del siglo XVII (al que incluso agregará otro del XVI, un auto acordado del mismo Consejo de Castilla), es evidente que comparte una imagen bastante negativa de la vida conventual, propia de ciertas elites europeas del siglo XVIII. ${ }^{56}$ Su postura, conviene decirlo, era minoritaria incluso en la Corte: la decisión final del Consejo de Indias, favorable a la fundación del Colegio Apostólico de Orizaba, constituye una prueba de ello. ${ }^{57}$ Empero, las bases estaban ya puestas desde esta época, los argumentos que se emplearán en el siglo XIX, aunque en un contexto radicalmente distinto, no irán demasiado lejos.

Apenas unos años después del dictamen del fiscal Posada, la guerra iniciada en 1810 dio especial actualidad a la utilidad de los conventos para el rey: las autoridades esperarán de ellos su más estrecha colaboración en el restablecimiento del orden. Y no se trataba sólo de elevar oraciones por el rey cautivo, bien que así lo hicieron y con abundancia, ${ }^{58}$ sino de utilizar el púlpito y el confesionario para la "justa causa". Los conventos orizabeños nuevamente nos proporcionan dos ejemplos: en 1812, el comandante militar de Orizaba emitió una recomendación a favor de los religiosos carmelitas orizabeños, que no sólo habían albergado a la tropa en su conven-

55 AGI, México, 1304, pedimento del fiscal Ramón de Posada, Madrid, 26 de enero de 1797.

56 Sobre la imagen de los religiosos durante el siglo XVIII español, Sarrailh, Jean: La España ilustrada de la segunda mitad del siglo XVIII, FCE, México, 1974, págs. 623-624, 630-632 y 640-643.

57 El Consejo de Indias revisó el expediente en tres sesiones después del último dictamen del fiscal y, el 21 de julio de 1797, resolvió recomendar al rey que accediera a la nueva fundación, mientras no se gravara a la Real Hacienda. AGI, México, 1304, extracto del expediente.

58 Véase por ejemplo: AGI, México, 2737, "Instrucción de lo que ha hecho este Apostólico Colegio de San José de Gracia de Orizaba desde principios de junio del año próximo pasado de 1808 hasta el día de la fecha a beneficio de la Nación y de su amado Monarca el Sr. D. Fernando Séptimo”, Orizaba, 29 de diciembre de 1809. 
to, sino que incluso lo habían acompañado en su retirada a Córdoba, lo mismo que a los destacamentos que defendieron dicha villa del asedio insurgente. ${ }^{59} \mathrm{Al}$ año siguiente, en 1813, el comandante militar de Puebla, el conde de Castro Terreño, a más de enviarles una felicitación a los frailes josefinos por haber misionado en la parroquia de San Agustín del Palmar, los exhortaba a seguir "ilustrando a los pueblos en sus verdaderos intereses en beneficio de la Religión y del Estado". ${ }^{60}$

Al igual que los militares, las primeras autoridades liberales no esperaban otra cosa de los frailes: la Junta Gubernativa de la provincia de Tabasco, órgano que había establecido el régimen constitucional en aquella región luego de obligar al gobernador a retirarse a Campeche, llamó a los frailes josefinos para que misionaran en Villahermosa, la capital provincial, a fin de mantener el orden. El Ayuntamiento constitucional de esa población solicitó incluso el apoyo del virrey Félix María Calleja para que esos religiosos permanecieran allí, por "el beneficio general que resulta tanto a los habitantes de esta provincia cuanto a la Nación", a lo cual accedió desde luego el gobernante, en aras del restablecimiento de la paz. ${ }^{61}$ Cabe decir que fue tal el compromiso de los frailes josefinos con la causa de Fernando VII, que el padre Bestard, en su carácter de comisario general de Indias, pidió para San José de Gracia la concesión del tratamiento de Real y la colocación de las armas reales en su puerta. ${ }^{62}$

No es de extrañar entonces que la independencia marque una auténtica ruptura en este caso: si antes se esperaba de los religiosos que predicaran desde el púlpito "el bien del Estado", después de 1821 se les exigirá abstenerse de toda referencia a la política. Cualquier insinuación en contra se hacía realmente sospechosa de la lealtad de los conventos. Así les sucedió a los mismos misioneros orizabeños, acusados de predicar contra el gobierno durante una misión en la villa de Córdoba en $1824 .{ }^{63}$ En ese con-

59 AGN, Diario Oficial, Gaceta del gobierno de México, t. III, núm. 265, martes 28 de junio de 1812, págs. 781-788. Arróniz, Ensayo, págs. 451-61.

60 AGI, México, 2737, el conde de Castro Terreño al cura de San Agustín del Palmar, Puebla, 6 de junio de 1813.

61 AGN, Misiones, 11, fs. 125-126v, Ayuntamiento constitucional de Villahermosa al virrey Félix Maria Calleja, Villahermosa, 20 de julio de 1813.

62 AGI, México, 2737, fray Juan Buenaventura Bestard a Esteban de Varea, Madrid, 2 de junio de 1819 .

63 AGN, Justicia Eclesiástica, 30, fs. 365-375, "Sobre la conducta de los misioneros del Colegio de San José de Gracia de la Villa de Orizaba, acusados de predicar contra el sistema de gobierno". Sobra decir que los frailes negaron rotundamente dicha acusación e informaron ampliamente del contenido de sus sermones. 
texto, no es extraño que reaparezcan los argumentos sobre la inutilidad de los conventos que había utilizado el fiscal Posada. Aún más, comenzará a formarse en la mente de algunos de los nuevos gobernantes la idea de que los conventos no eran sólo inútiles, sino sobre todo centros potenciales de una conspiración. Una y otra idea las expresó claramente el jefe político de Orizaba, Vicente de Segura, en un amplio informe al gobernador de Veracruz en 1827.

Vicente Segura era el representante de un Estado liberal, de un gobierno representativo fundado en la soberanía popular, y no un jurista encargado de defender las regalías de la Corona. Empero, no puede negarse el parentesco de sus argumentos con los del fiscal Posada. Los frailes, de acuerdo a Segura, acumulaban bienes: a pesar de las dificultades económicas por las que pasaba la villa, "adelantaban extraordinariamente la inmensa fábrica material de su iglesia, colegio y huertos de recreación", disputaban a la parroquia los bienes de la orden tercera, ${ }^{64}$ comerciaban con "mortajas, cordones, medallas, escapularios, rosarios y otras sacaliñas", y sobre todo:

gravitan desesperadamente sobre los pueblos del Estado con unas increíbles contribuciones llamadas limosnas, exigidas con violencia por medio de una partida de legos que a la manera de una gavilla de ladrones se esparcen por los pueblos, campos y rancherías $[\ldots]$ con perjuicio de la Hacienda pública y diezmos.

No es de extrañar que la imagen de la plaga, que ya hemos visto en el dictamen de Posada, si bien no se encuentra en el informe de Segura, reaparece en cambio en una carta anónima previa, firmada únicamente por "un patriota", en la que se denunciaba a los frailes ante el ministro de justicia y negocios eclesiásticos, con argumentos muy cercanos a los del jefe político. ${ }^{65}$

El funcionario apuntaba además que los frailes josefinos no cumplían con su labor: "la verdadera administración de los sacramentos carga toda sobre el cura y los vicarios". La discusión sobre la función de los religiosos en la distribución del pasto espiritual, como en Posada, volvía así a hacerse presente, aunque en sentido inverso: Segura no dice que sean inne-

64 Las órdenes terceras estaban formadas por hermanos seglares, tanto varones como mujeres, y aunque bajo la supervisión de un fraile comisario, eran prácticamente autónomas. La de Orizaba estaba instalada en la parroquia porque era anterior a la fundación del Colegio de San José de Gracia y los frailes trataron de trasladarla a su convento, dando origen a un largo conflicto.

65 AGN, Justicia Eclesiástica, 80, fs. 300-301v, "Un patriota" a Miguel Ramos Arizpe, Orizaba, $1^{\circ}$ de julio de 1826. 
cesarios, sino que incumplen con su obligación. El funcionario abonaba a la imagen de unos religiosos no sólo ambiciosos, sino holgazanes: "los días festivos a las nueve de la mañana ya no hay una misa en su iglesia a pesar de la suma necesidad de la población porque el chocolate se ha de tomar temprano y la constitución prohíbe estarse en ayunas mucho tiempo". ${ }^{66}$

Más importante incluso que todo lo anterior era que Segura denunciaba que el Colegio Apostólico de San José de Gracia se había convertido en el centro de una junta "corro-masónica" encabezada sin embargo por un laico, el español Francisco del Puy y Ochoa. Muy lejos de ser útiles al Estado, los religiosos, con su influjo y su labor en el púlpito y el confesionario, "no sólo han impedido sino aun retrasado los progresos de la causa pública". ${ }^{67}$

Notemos nuevamente que el sentido de "público" ha cambiado, Segura incluso distingue entre el "vecindario" y la "causa pública" que otrora parecían intercambiables. El jefe político utiliza un vocabulario mezclado: en su reporte se encuentran fórmulas muy tradicionales, como "público y notorio" para señalar algo conocido de toda la población, u "hombre de opinión" para referirse a un personaje con prestigio; en cambio utiliza también nuevas expresiones: "autoridades públicas" como sinónimo de gobierno del Estado y de la Federación, "asuntos de Estado", como asuntos políticos, "causa pública", la de la independencia, la de la consolidación del Estado, en la que desde luego el funcionario se encontraba absolutamente comprometido y que los religiosos ponían en peligro. Conforme avanzaba el tiempo, Segura parecía más decidido a afrontar a los religiosos: “¿se quedarán impunes — preguntaba al gobernador de Veracruz - los excesos de un pueblo que compromete el honor de su gobierno?". ${ }^{68}$

En suma, Posada y Segura coincidían en una misma idea: los frailes eran una plaga para los pueblos, que redundaba en un perjuicio público. Había diferencias, sin duda, pues en el primero, el público era la Corona y en el segundo, un Estado liberal. El fiscal y quienes coincidían con él en la Corte de Madrid, disponían de medios relativamente limitados para impo-

66 AGN, Justicia Eclesiástica, 78, fs. 4-6, Vicente de Segura al gobernador de Veracruz, Orizaba, 31 de enero de 1827.

67 Idem.

68 Vicente de Segura al gobernador de Veracruz, 2 de mayo de 1827, trascrito en: AGN, Justicia eclesiástica, 80, fs. 302-305, Juan José Espinoza de los Monteros al secretario de justicia y negocios eclesiásticos, México, 16 de mayo de 1827. 
ner sus puntos de vista desde el otro lado del Atlántico. ${ }^{69}$ Su negativa aparece aislada en un expediente que pasó por las manos de funcionarios del gobierno provincial de Veracruz, la Corte de México y la de Madrid. En cambio, en 1827 la opinión de Segura era compartida por otros miembros de la elite orizabeña y veracruzana, y además contaba con la milicia cívica y, rivalidades políticas de por medio, con la guarnición federal de la villa, para imponerse.

Considerados "inútiles" o "peligrosos", la sola alternativa que les quede a los frailes para justificarse con los nuevos representantes de la "causa pública" será su total alejamiento del mundo. En 1829, expuestos los religiosos josefinos a una posible expulsión por su condición de españoles, las representaciones que a su favor giren las autoridades locales insistirán en su total abstinencia en materias políticas. Paradójicamente, quienes antes hacían alarde de su papel en el sostenimiento del Estado, debían ahora presentarse como simples observadores que intervenían "sin más interés que el de la caridad". ${ }^{70}$ Aún más, el mayor beneficio que podían aportar los frailes al Estado era precisamente su total renuncia a toda intervención en la materia. Lo decía expresamente el jefe político orizabeño Vicente Prieto Fernández al aclarar que los frailes: "en el ejercicio de su ministerio se ciñen a la predicación del Evangelio sin mezclarse en los asuntos políticos, con lo que lejos de causar el menor mal, proporcionan mucho bien no solo a esta población sino a toda la República". ${ }^{71}$

Aunque algunos religiosos lograron así salvarse de la expulsión, se encontrarán pronto con una amenaza mayor: la exclaustración. La opinión expresada por Vicente de Segura se convertirá en mayoritaria en la IV legislatura estatal veracruzana de 1833-1834.

30 de noviembre de 1833. En la capilla de la orden tercera franciscana de la ciudad de Veracruz tiene lugar la reunión de la legislatura estatal. ${ }^{72}$ Es una sesión importante, se han reunido allí las dos cámaras que componen la legislatura y el principal punto del orden del día es la discusión de un dictamen de las comisiones unidas de justicia, puntos constitucionales e

69 Los ministros regalistas, señala Annick Lempérière, estaban concientes de que "el proyecto de modernización sociocultural sólo podía ser llevado a cabo, salvando la coacción, mediante la cooperación de los actores tradicionales, obtenida por la vía legislativa, la persuasión y la negociación". Lempérière, "Recepción", pág. 203.

70 AGN, Expulsión de Españoles, 35, fs. 107-108, fray José Camarasa, fray Lorenzo Socíes, fray Juan Roselló y fray Joaquín Ferrando al presidente de la República, Orizaba, 15 de abril de 1829.

71 Ibidem, fs. 108, 109-109v, recomendación de Vicente Prieto, Orizaba, 18 de abril de 1829.

72 Seguimos aquí los acontecimientos narrados en Carbajal, Política, págs. 104ss. 
instrucción pública, cuyo objetivo es proporcionar fondos para un gran proyecto de educación estatal. Se realiza la lectura del proyecto de decreto en el que los legisladores se muestran radicales: el artículo primero, sin hacer ninguna declaración sobre la propiedad de los conventos, dispone de ellos y de sus bienes y los destina "al fomento de la educación y beneficencia pública"; empero, hace una excepción: de los núcleos franciscanos. Excepción tal vez de cortesía, pues el salón de sesiones no es sino parte de un convento de esa orden, o tal vez una previsión para evitar demasiados escándalos, ya que así subsistiría un convento en cada una de las cuatro grandes poblaciones veracruzanas (Veracruz, Orizaba, Xalapa y Córdoba). En cualquier caso, los legisladores se preocuparán muy poco de hacer notar esta distinción en sus discursos.

Pasaron a la tribuna varios oradores, todos en apoyo del decreto, tal vez no tanto buscando convencer a sus compañeros legisladores, cuanto a sus "comitentes", los habitantes del Estado de Veracruz. No es de extrañar que el acta de la sesión se imprimiera casi de inmediato por mandato del gobierno estatal. ${ }^{73}$ Los oradores fueron prácticamente unánimes en presentar una imagen bastante negativa de los conventos: además del estado casi total de abandono en que se encontraban, la disciplina se había relajado y los legados de los bienhechores se dilapidaban por los escasos religiosos que en ellos residían. ${ }^{74}$ Nuevamente, como en Posada y en Segura, los conventos no hacían otra cosa que estancar bienes, reducir las manos productivas y desperdiciar sus riquezas.

Notemos sobre todo la redacción del primer artículo del decreto: los bienes de los conventos se destinan a la educación y a la beneficencia pública. Dedicar los conventos a esos fines, era precisamente el objetivo de los Ayuntamientos que hemos citado en el apartado anterior, pero conservando a los conventos como tales. Los legisladores no encuentran ya sentido a ese intento, que concedía aún un papel importante a los religiosos y es ahora el Estado el que organiza un sistema de educación y beneficencia, sin los frailes. No importaba si ya algunos de los conventos eran hospitales o impartían educación elemental, lo decía claramente el diputado Manuel

73 La sesión se publicó por la imprenta de Blanco y Aburto, instalada en la Oficina del Gobierno. Sesión del H. Congreso de Veracruz, en que se discutió y aprobó el Decreto que declara de la pertenencia del Estado algunos Conventos y sus propiedades, Veracruz, Impreso por Blanco y Aburto en la Oficina del Gobierno, 1833.

74 Véanse las intervenciones de los diputados José Nicolás Esteves, Manuel Mesa y Joaquín Guevara, Sesión, págs. 9-31; Carbajal, Política, págs. 104-109. 
Mesa: "Los conventos comprendidos en el artículo que se discute, son inútiles á la sociedad en el orden moral y en el civil". ${ }^{75}$

El Estado, decía también Mesa, debía disponer de esos bienes, por una exigencia de la "conveniencia general", ${ }^{76}$ la nueva "causa pública", para la cual los conventos y sus frailes no reportaban ya ninguna utilidad.

\section{4: La vuelta del público}

Desde la perspectiva de la "pública utilidad" tradicional, los conventos seguían siendo útiles, tanto para fines antiguos —el honor de las corporaciones municipales - como para fines modernos, encbezados por la beneficencia y la educación. En la perspectiva de la nueva "causa pública", la de la Corona primero, la del Estado liberal más tarde, los conventos acabaron por resultar o inútiles o peligrosos. Tales, a grandes rasgos, fueron las dos grandes posturas que se han ido desarrollando en la provincia de Veracruz entre 1786 y 1834. A primera vista, parecería que la segunda, la más moderna, la que contaba con los recursos del Estado liberal, habría de imponerse, de la mano de la razón y la filosofía, como proclamaban los legisladores en noviembre de 1833.

Es preciso decir, sin embargo, que el "público" tradicional tenía también apoyos firmes. La historiografía reciente lo ha mostrado claramente: en los reinos americanos donde las corporaciones urbanas compartieron con la Corona atributos propios de la soberanía que se vieron consolidados en la crisis de la monarquía a principios del siglo XIX, gracias especialmente al fortalecimiento del municipio por la Constitución de 1812. Las repúblicas nacientes heredaron por ello una disputa entre soberanías, en la cual la valoración de la utilidad de los conventos constituye sólo un aspecto. ${ }^{77}$ La razón y la filosofía se enfrentaban con una tradición fortalecida por los procesos más recientes y que sabía encontrar argumentos en el nuevo lenguaje.

En agosto de 1826, cuando la legislatura estatal estudiaba la solicitud del nuevo convento carmelita de Xalapa que hemos citado páginas atrás, apareció en la prensa local un comunicado bajo seudónimo que argumenta-

75 Sesión, pág. 15.

76 Idem..

77 Véase sobre este tema: Annino, Antonio: “Soberanías en lucha”, en Guerra, François-Xavier y Annino Antonio (coords.), Inventando la nación. Iberoamérica. Siglo XIX, págs. 152-184. 
ba ampliamente sobre la falta de facultades del Congreso para tratar dicho asunto, que correspondía exclusivamente al Ayuntamiento. En dicho comunicado se aprecia más de una hibridación entre el vocabulario liberal, que en este caso incluye amplias citas de Benjamin Constant, y el tradicional del Antiguo Régimen. Del vocabulario liberal, el autor recuperó la defensa de Constant de los intereses de los municipios frente a la intervención de la voluntad general. Una defensa, debemos subrayarlo, construida alrededor del concepto moderno de individuo, pero que a nuestro anónimo Amigo del buen orden, le sirve para argumentar a favor del respeto a la jurisdicción del "cuerpo municipal". A ella tocaba, insistía el comunicado, "abrir un camino o acueducto, fabricar un templo o capilla, erigir un hospital, escuela u orfanato y hacer otro establecimiento de beneficencia pública" ${ }^{78} \mathrm{La}$ defensa del interés individual servía aquí de argumento a favor del público tradicional.

Así pues, no nos sorprende el final de la coyuntura de 1833-1834 en Veracruz. Ciertamente, los jefes políticos de Veracruz, Xalapa y Orizaba lograron tomar posesión de los conventos de sus respectivas cabeceras en 1834, mas diversos pronunciamientos, cuyo desarrollo no cabe analizar aquí, acabarán no sólo con el proyecto educativo estatal, sino incluso con los poderes estatales mismos. ${ }^{79}$

Los conventos se reabrieron, desde luego, pero bajo la vigilante tutela de las corporaciones municipales: en Orizaba, como hemos señalado, el Ayuntamiento logró restablecer el antiguo convento hospital de San Juan de Dios, pero ahora bajo su tutela; en Veracruz, el gobierno local obtuvo la administración del antiguo convento hospital de Belén, ${ }^{80}$ mientras que las autoridades de Córdoba intervinieron de manera más notoria en el gobierno del convento de San Antonio de Padua. ${ }^{81}$

Así pues, pareciera que la "pública utilidad" se impone, y son los ayuntamientos, constitucionales ciertamente los ejecutores, pero como hemos visto, herederos en buena medida del espíritu corporativo y de la idea de soberanía de sus antecesores, de quienes dependerá, al menos por un tiempo, la subsistencia de los conventos y de sus residentes.

78 El Oriente, núm. 686, Xalapa, 7 de agosto de 1826, pp. 2833-2834.

79 Véase: Carbajal, Política, págs. 125-131.

80 Archivo Histórico Municipal de Veracruz (AHMV), 171, 234, fs. 64v-65v.

81 Archivo Histórico Municipal de Córdoba (AHMC), 90, "Convento de San Antonio". 